\title{
Do we really want a future as qualitative psychologists?
}

\begin{abstract}
In this article I pick up some threads from the contributions in the previous special issue of IPSB dedicated to the future of qualitative psychology, and elaborate them around two main points. The first is the status of qualitative psychology as a social and institutional category; the second is what we mean by experience.

As concerns the first point, I have argued that using the label of qualitative psychology may separate us from the rest of psychology, also creating a false impression of homogeneity among qualitative approaches and a false opposition with quantitative methods. Implications for teaching as well as doing research are discussed.

The second issue has to do with experience as the object of qualitative psychology investigation. I have proposed three ways to formulate experience in research avoiding naïve assumptions about accessing it directly through language. These are 1) experience as experience of the researcher, 2) experience as situated intersubjectivity, and 3) experience as expression. I discuss how being clearer about definitions of experience and going towards engaged forms of research could safeguard the integrity of both researcher and participants.
\end{abstract}




\section{Do we really want a future as qualitative psychologists?}

\section{Are we self-segregating?}

I am in two minds about considering the flourishing of dedicated journals and conferences (Demuth, 2015a) as an indicator of success. On the one hand it certainly means that qualitative psychologists are taking more space on the scene and affirming their rights to be heard; on the other hand, creating defended, alternative venues for publications and presentations may reiterate and perhaps reinforce our minority status. There are journals of the psychology of this-and-that and there are journals of qualitative psychology of this-and-that. Of course, forcing our way into mainstream journals in simply not viable most of the time, but perhaps it would be a good parallel strategy to create journals with a focus on either specific topics or epistemological stances which are elective for qualitative psychology, like the very journal publishing these lines, or open to qualitative research in general like the recently established Journal of Interactional Research in Communication Disorders and the brand new Research for Children and Social Interaction. This would mean qualifying the kind of psychology we do, rather then forcing us to difficult cohabitations and bestow on us a label that none of us identifies with. 
The same can be said for teaching Qualitative Methods under such term. I teach the qualitative part of both undergraduate and post-graduate units including quantitative and qualitative methods, and I completely agree with Terkildsen and Petersen (2015; by the way, how interesting to have the students' perspective in the special issue) that in doing so we build the false perception of all qualitative methods sitting close to each other and roughly at the same distance from those quantitative types across the room- which is not the case at all. As we know, but is worth repeating, some qualitative approaches are more distant from each other than from quantitative ways of reasoning. Those which include coding data and identifying relations between variables, for example, are not conceptually alien to what experimental cognitive psychologists do, whereas the practice is incompatible with ethnomethodological or critical perspectives; or treating written texts as stand alone items, as certain forms of discourse analysis concedes, is also closer to quantitative content analysis and at odds with what other qualitative approaches- such as ethnography - that deem necessary to investigate how texts are produced and used as well as their content ${ }^{1}$.

Terkildsen and Petersen's (2015) suggestion that students should be taught the epistemologies rather than the 'tools' (besides making me want to hug them) is also worth pursuing. Contextualizing the different qualitative methods in the history of psychology and its different epistemologies would break the image of homogeneity between them and show their full legitimacy within the discipline.

A recurrent paradox in the history of knowledge is that when certain things are so culturally engrained that never need to be mentioned, they may be entirely

\footnotetext{
${ }^{1}$ See ten Have, 2004 for a systematic comparison of different qualitative methods and their compatibility with ethnomethodology.
} 
forgotten, their being tacit subtracting the resources for reclaiming them. De Santillana and Dechend (1996 p.4), discussing the disappearance of the once firmly established connection between astronomic knowledge and mythology, note that: "Ancient historians would have been aghast had they been told that obvious things were to become unnoticeable"2. The forebears of psychology, as Brinkmann (2015) reminds us, did not refer to what they were doing as qualitative or especially distinct form experiments, as there was no need to justify or give a separate label to central psychological practices such as examining subjectivity or studying single cases. Now that what was marginal in psychology has become central stage, and vice versa, it is difficult to bring back this awareness into the short memory of the discipline. To come back to our point, if the different research methods were grounded in their history and theory of knowledge, the absurdity of having to fight for doing research on the very subject matters psychology was born for would stand out more clearly. However, I have met a number of difficulties to include such notions when teaching the qualitative part of units which also comprehended quantitative methods. After giving students batteries of techniques in the first half of the course, introducing historical and theoretical content as a premise to qualitative methods only confirm them that qualitative methods produce a psychology in inverted commas, full of caveats and fine distinctions, and that it is safer to stay away for it. (The fact that history of psychology is not a required subject in psychology courses does not help either: revealing that Wundt was much more interested in cultural psychology than in

\footnotetext{
${ }^{2}$ Here's how they continue, if you are curious: “Aristotle was proud to state it as known that the gods were originally stars, even if popular fantasy had later obscured this truth. Little as he believed in progress, he felt this much had been secured for the future." (de Santillana \& Dechend, ibidem)
} 
his experiments is not going to be much of a scoop if you are unaware of Wundt's role in establishing the paradigm of experimental psychology). This is just to say that a commitment to a different psychology might require getting involved at an organisational level, and try to shape our teaching in sensible ways. We will be soon separating the qualitative from the quantitative methods module in my department, and we will try not to have a twin denomination, but I doubt I will be able to teach a unit called, say, Researching Human Activity and Experience, rather than Qualitative Methods. It would be a much clearer title though, and abandoning the quantitative/qualitative opposition would also help undoing the belief that in studying these things we cannot 'count', which is also untrue. ${ }^{3}$

One last thing I would like to say about the risks of hardening the boundaries of qualitative psychology is that in so doing we reinforce our insularity. We need to go back to the forebears also in terms keeping up with the cousin disciplines anthropology, sociology, literary studies, and increasingly human geography. I agree with Brinkmann (2015) that multi-disciplinarity has got the potential for seriously innovative endeavours in the social sciences; however in psychology there is a strong tendency to reinvent the wheel, and qualitative psychologists have often exploited the fact that we can count on an audience of psychology-only readers for rebranding

\footnotetext{
${ }^{3}$ As Schegloff (1993, p.114) put it, we can count, as long we make sure that 'we know what the phenomena are, how they are organized, and how they are related to each other as a precondition for cogently bringing methods of quantitative analysis to bear on them'. In 1993 Schegloff deemed premature a statistical approach to the study of talk in interaction, but he argued that the attention to each and every instance of a given phenomenon also has numerical significance: 'one is also a number' (ibidem, p.101).
} 
concepts and theories from neighbouring disciplines, or hair-splitting an analytical practice so to create one's new cute acronym. In a way, qualitative psychology has become a brand in itself, and not one that up to now has favoured interdisciplinary recruiting and collaboration.

\section{Experience of what? And of whom?}

As many of the topics that are discussed in the special issue, the researcher-participant problem is at once ethical and key to creating better science. Tateo (2015) strikes right into the heart of the question, I think, when he discusses this relation together with the problem of experience. A point both he and Demuth's (2015a) make clear, so I will not reiterate it at length, is that the basic equivocation about qualitative research is that it is about the interviewee's experience, where experience is the pre-existing internal content of the individual heart/mind that the interviewer will-with the aid of some 'skills' of course - liberate. I think that if we make the effort of clarifying the ways experience can be studied we can attack both these fronts simultaneously. Here's my twopence.

Experience as experience of the researcher. As cultural anthropologist Kapferer (1986) says, "I do not experience your experience. [...] I experience my experience of you" (Kapferer, 1986: 189; see also Bruner, 1986). Bearing this in mind can strengthen two existing practices in qualitative psychology, which are not yet as established as they could be. The first is treating the researcher's experience as an asset in the process of scientific creativity and accountability, also strengthening 
'second person' approaches (Reddy, 2008); the second is developing participatory research.

From an ethnomethodological standpoint, if I stay in the position of the observer I can access only half of the process of making sense in everyday life: my experience is one-sided and I do not have the natural confirmation of the other's action toward me that would validate my interpretation (and theirs of mine ad so on: Rawls, 2006). Engagement is thus a requisite for 'quality' findings, and one that can bring into psychological knowledge an array of sources that are unavailable from a mere observer position. As discussed by Reddy (2008, pp.34-6), engagement and disengagement necessarily alternate in the research process, but disengagement is not equal to detachment and leaving participants beyond a glass wall.

Forms of engagement can vary, and it is not the place here for discussing all the options for engaged research in different fields of inquiry. It is interesting though that neuroscientists have noticed how a shift in the position of the researcher can produce better science, and have now begun to incorporate second person approaches into their observational paradigms (Schilbach et al., 2013; see Tateo, 2015, for an illustration of the different researcher's positions as derived from Peircean semiotics).

Speaking about the experience of the researcher, Bruner (1986, p.9) says: "Most good ethnographers, interestingly enough, reintroduce vitality in their descriptive accounts by including illustrative snatches of personal narrative, bits of biography, or vivid passages from their fieldnotes [...] In effect the experiential component return to the account as a by-product rather then an explicit object of research". This was 1986, and a lot has changed in anthropology since ${ }^{4}$; in

\footnotetext{
${ }^{4}$ To an extent: the 80 s have probably seen the greatest innovation on this matter. And it is often the case that first person reflexive accounts are made the subject of separate
} 
psychology, however, we still feel lucky if we get any of that. Dating problems aside, what the quote helps us see is that the problem is also centrally one of writing. The fact that Bruner uses the word 'vitality' is revelatory: I am sure we can all remember reading a qualitative article and really enjoying those fragments in which the study came alive, the uncertainty and openness of doing research vibrating again in the description. However, we treat these fragments as luxury, and we use them with extreme moderation. The problem of course is that this kind of things sounds perilously 'subjective', and the more they seep through the more there is fear that they may make a study weaker to outsiders' eyes. This is just another reason, though, why it could be worth making a point of it, and arguing that we are in fact trying to offer a more credible and more informative science (Freeman 2011).

We should deal with the question of subjectivity upfront in our teaching as well, making it one of the defining features of qualitative approaches. I found Parker's (2004, pp.26-30) way of explaining views on subjectivity and how to put them right particularly helpful: “Th[e] 'merely subjective' version of subjectivity is misleading because it overlooks the difficult conceptual work that we need to engage in to make subjectivity part of the research, and it reduces subjectivity to something that only pertains to the individual researcher as if it were hidden inside them, waiting to be revealed to the reader $[\ldots]$ To talk about 'the position of the researcher' is not at all to wallow in one's own bad (or good) feelings about what happened in the research, to spill your guts about what you felt, but to explore how that particular form of subjectivity came to be the way it was by virtue of the particular institutional relationships that were drawn up and recreated so to make it intelligible and

publications rather then being interwoven with the object of study, or even become a separate method, like autoethnography. 
accountable". The concept is clear; how to transform it into a writing practice is less immediate, especially when we want to make it part of our very standard way of exposing research findings. However, dedicated works that explore these dimensions specifically can also help building a shared writing practice. Medved and Brockmeier (2014) offer a useful reflexive exploration of the researcher's position in a study involving Canadian First Nation women. The authors show how to articulate an analysis about the conceptual apparatus that any investigation brings to bear on the dialogue with the participants, exploring for example the zones of opacity around the use of a term like culture or the genre of personal narratives the women adopted.

So, to conclude, we have to be really careful not to contribute to the demonisation of subjectivity, which can also happen when adopting the rhetoric of rigour, and instead indefatigably promote forms of writing that encourage engagement in the research process and identifying the position of the researcher in its multiple determinants.

Following up from the previous discussion, the distinguishing mark of all qualitative research should be to seek intimacy (Williams \& Gantt 1998) with whom and what we study, but this is impossible if we do not turn around many tacit assumptions about the role of participants in research. Participatory research was repeatedly brought up in the special issue; Brinkmann (2015) mentions it as one the new creative ways of making psychology that are happening at the fringes, and Tateo (2015) argues that the curiosity of the participant is as valid as that of the researcher. I think that seeking intimacy with and give recognition (Todorov, 2001 Ricoeur, 2004) to the participants in our studies can have deep epistemological consequences; ethical and scientific objectives meet here as recognition reinstates the integrity of both the researcher and the participants. 
An equal footing and an active involvement may be achieved through different strategies, but broadly speaking it entails annexing the participants' experience by making them researchers as well, sharing the culture of research and finding ways to merge researchers' interests and concerns of participants - or the other way around. The practice is consequential not only from the participants actually involved: a clear example comes from the field of communication disorders and intellectual disabilities. Experimental, 'detached' studies perpetuate images of deficit and difference, widening the distance between people with typical and atypical competence and reproducing definitions of conditions that are partial or incorrect. Involving participants has permitted to capture the sense-making, relation-seeking efforts of people with different mental health conditions and with communication impairment, enabling intersubjectivity and building more detailed and accurate pictures of what a condition entails and how to better support those who live with it (Williams, 2001; Biklen, Attfield 2005, among others).

Understanding in participatory research comes from a prolonged, sustained and mutual relationship (although not necessarily a symmetrical one point-to-point); interpretations and new questions as well as ways to pursue them develop within a project; the research changes and the participants change with it; the implication here is that the experience this process will eventually make available to the scientific community is not a pre-existing property of the individuals, but a forward-looking, goal orientated and intersubjective achievement. Which brings us to the second way of conceiving of experience.

Experience as situated intersubjectivity. Staying loyal to experience means investigating the details of the practices members bring to the situation, and all what 
the situation entails (von Helm, 2014). It is an ecological approach, which reshapes itself artistically around the object of research, finding ways of catching the action of participants in their orientation to each other and in a space and time that is meaningful to them.

One fundamental aspect of human psychology that experimental approaches and many interview-based one - are doomed to fail seeing is that human life is organised into domains which have their own distinct organisation in terms of time, environmental structures and interactional frames that come into play together (for examples of domains in relation to socialisation practices see Nucci \& Weber, 1995, Fasulo, Lloyd \&Padiglione 2007). Conversely, ecological, situated approaches are interested to capture precisely those interrelations, and are adopted by various strands of Anthropology, Cultural Psychology and Ecological Psychology (Hutchins, 1995: Lave, 1988 Costall \& Leudar, 1996 Goodwin, 2000, 2002). Situated approaches were was advocated even earlier on by Garfinkel, Goffman, and Bateson, all recognising the primacy of 'situation' and its specifics. Bateson has particularly evocative ways of describing what differs in this stance, as exemplified by his recommendation for 'the substitution of a temporalized "eco-logic" for the timeless "logic" which previously served as a model or image of mind.' (Bateson \& Donaldson, 1991, p.xvii; on the issue time in psychological inquiry see Fogel, 2011). Again, this is a way of framing experience that does not imply pursuing the rendering of consolidated feelings and thoughts, but that tries to get closer to the moment-by-moment, action-tocounteraction perspective that characterises activity in context. 
Experience as expression ${ }^{5}$. Finally, we may want to explore how people give shape to experience in culturally inflected forms. These may entail narratives variously constructed or performed, artistic creations, and possibly collective enactments of ritualised or symbolic activities. Investigating experience through its expressions does not collapse one onto the other; on the contrary, it looks at how available cultural resources support the entextualisation of subjectivity, and how texts and performances refresh and renew the cultural resources that makes them intelligible. As anthropologists see it, in this perspective we leave to other people to define the unit of investigation (Bruner, 1996), as they choose the shape in which to articulate their experience.

The psychological explorations of the interplay between subjectivity, culture and expressive media has happened mostly outside psychology itself, with the study of literary narratives, fictional or autobiographical, by literature scholars such as Eakin and Olney (with few exceptions; see Brockmeier, 2008, 2009). These works show that that the more refined, elaborated and properly artistic a narrative, the more powerful it can be in illuminating the complexities of our reflexive relation to ourselves and the world. Life-stories and narratives in interviews can be enlisted amongst expression of experience, but only if we also consider the cultural resources they draw upon and we treat them as occasioned performances.

At present, the treatment of narratives in qualitative psychology is highly problematic (Atkinson \& Delamont 2006). One problem is the narrow interpretation of narratives as always or mainly doing identity work, or positioning. First of all,

\footnotetext{
${ }^{5}$ I owe the formulation to the group of anthropologists which have worked to the articulation of an anthropology of experience (Turner \& Bruner, 1996).
} 
personal identity often includes or is defined by the narratives we build about others, places, and other non strictly autobiographical events (Fasulo, forthcoming).

Secondly, narrative is a machinery for the production of sense that is applied across social and natural phenomena, and we use it for the organisation of knowledge far beyond the limits of the autobiographical sphere, as is evident when looking at conversational narratives (Fasulo Zucchermaglio 2008). Another problem in the way narratives are used is that meaning is extracted from them as if it were readily available; stories, however, are not uni-dimensional in their meaning, and are not about routines or all-clear facts: they often arise precisely to work through breaks from expectations and opaque events.

Ruppel and Mey's (2015) reflections on how to do justice to narratives within the Grounded Theory approach is welcome, but in a way is more revealing of problems than of solutions, a fact they do not try hiding. Let me give an example. In putting together some material for a workshop, I recently went through a collection of life-story interviews gathered by $3^{\text {rd }}$ year students for their coursework. I selected a few that seemed at once more elaborate and more enigmatic, and seemed promising for a good discussion. Together with the workshop participants, we worked out that the interviews made sense only if examined in their entirety as a gallery of selected images that worked together toward the suggestion of meaning ${ }^{6}$. Take the interview of a woman who had left London (where she had spent all her life) in her middle age, for a more rural and isolated place in England. There was a lot of bitterness about that turn of events throughout the interview, and a marked before and after in the narrative

\footnotetext{
${ }^{6}$ Perhaps not by chance these are interviews in which students had selected participants knowing that there was a good story there, and during which they did not hide their familiarity with both the interview and the story.
} 
structure. But what was that she felt she had lost? She never stated it in an explanatory fashion. The woman recalled instead a series of stories about London, all from her childhood (where many life myths notoriously come from). These included witnessing the first V2 rocket launched by the Germans; her mum moving heavy furniture from place to place as they got hit, resolute not to leave the city; herself, 4 years old, offering flowers to the Queen Mother who went to visit the hospital where she was being cured of pneumonia, and spending nights in tube stations as it is often seen in war documentaries and photographs. Breaking down these stories, even according to a story grammar model as proposed by Böhm (cit. in Ruppel and May 2015) would not take us anywhere near the atmosphere and imagery this part of the interview on the whole conveyed. We felt that at least one thread running through was that London was a place where history with the big $\mathrm{H}$ happened, and could rub off on ordinary people any time ${ }^{7}$, whereas this kind of potentiality had been taken away from the woman's life horizon in the new place.

My point is that narratives are always oblique, creating meaning in synecdochical fashion, and have multiple entry points (some of which can get lost if the interviewer goes down a different path). This openness is intrinsic to human symbolic expression, and qualitative methods that try to reabsorb it by breaking them down into smaller unit of meaning simply miss the point and its psychological

\footnotetext{
${ }^{7}$ The concept of the proximity of the big and the small, the celebrities and everyone, is not only visible in the collection of stories but also in a break-through into reported speech, during the telling of the hospital episode: "Strangely enough while I was in there her majesty the queen mother came to the hospital to visit because Buckingham palace had been bombed as well and she then made the famous statement "I can look the East End in the eye now" because her home had been bombed as well ..." .
} 
significance. It is also not wise to put the method of analysis before the research question and the data, as if the method were the unchangeable part and the rest had to adapt to it (Demuth, 2015b). As for narratives, it may be better to stay with the more humble idea that we can use narratives to open up "regions of truth" (Freeman 2011) to which to go back again and again.

Finally, it may worth considering that by studying artefacts already existing naturally occurring data - we can study not only problems and difficulties but also the resilient processes, the artefact itself often being part of the solution. The representation of experience in cultural forms is a reflexive and often self-therapeutic process. Whereas this kind of information can be elicited in interview as well, the fact that a certain narrative or artistic project has been undertaken spontaneously at a certain point in a person's life, and in a certain form, gives us more information than can appear in an interview about how cultural resources and narrative representations function in supporting people's psychological needs. There are many possible examples here; Eakin's (2014) analysis of Sartre's autobiographical writing is an unforgettable (for me) lesson in how since childhood we actively work on our negative experiences by shaping them into cultural forms, always looking forward to the next instantiation.

To conclude this long section, I can only add that most of the time referring to experience as the objective of a study may be unnecessary if not confusing. Like identity $^{8}$, the term may have accumulated too much history for us to be able to demystify inappropriate uses; a term that covers so many declinations may also have

\footnotetext{
${ }^{8}$ For arguments on the limited utility and frequent abuse of the notion of identity in social science see Bendle, 2006, Brubaker \& Cooper, 2000, Kulick, 2005; see Fasulo Piazza, 2014 for a review.
} 
limited heuristic value. As the Buddhists say, I offer these thoughts for reflection today.

\section{Conclusions}

I have examined two main issues with the aim of understanding what creates misleading representations of qualitative psychologists and what are the ill-defined areas in the methodological practices themselves.

The first has to do with the label 'qualitative' itself; I have argued that it may separate us from the rest of psychology, creating a false impression of homogeneity within the field and a similarly incorrect polarity with quantitative methods. The issue of diversity within qualitative methods has been argued many times before, but as we are in the process of creating even more events and institutions with this denomination, it may be worth also thinking about alternatives.

The second issue has to do with experience as the target of qualitative inquiry; together with the prevalence of interviews in qualitative research, this notion is contributing to a portrait of qualitative psychology as naïve beyond its borders, and is producing theoretically flawed research within them. I have proposed three ways to formulate experience as an object of research without losing sight of the facts that it can be never be captured first hand or in its raw state, that it is not exclusively individual and that it is phenomenologically forward looking. These are 1) experience as experience of the researcher, 2) experience as situated intersubjectivity, and 3) experience as expression. I have attempted to show how embracing these definitions of experience in qualitative research would entail building intimacy with and 
recognition of the research participants, while acknowledging and creatively deploy the subjectivity of the researcher as well. I have argued that the practices mentioned would safeguard the integrity of both researcher and participants, during the research process as well as in the final write-up.

I wish that the extremely fruitful discussion that was opened with the previous issue of JPBS by Carolin Demuth and the workshop contributors will keep going, with even more voices joining in the debate. I would have liked to elaborate more on the question of writing, which retrospectively influences so many of the decisions we take in our research, but I have been lingering too much already. I look forward then to a next event in which we can bring together our views again, focusing on how to write about the qualities of human life.

\section{References}

Atkinson, P., \& Delamont, S. (2006). Rescuing narrative from qualitative research. Narrative Inquiry, 16(1), 164-172.

Bateson, G., \& Donaldson, R. E. (1991). A sacred unity: Further steps to an ecology of mind. Harper One.

Bendle, M. (2002). The crisis of identity in high modernity. British Journal of Sociology 53(1), 1-18.

Biklen D. \& Attfield R. (2005). Autism and the Myth of the Person Alone, NYU Press Brinkmann, S. (2015). Perils and Potentials in Qualitative Psychology. Integrative Psychological \& Behavioral Science,. 49 (2). doi:10.1007/s12124-0149293-z. 
Brockmeier J. (2008). Austerlitz's Memory. Partial Answers 6.2: 347-67.

Brockmeier J. (2009). Stories to remember: Narrative and the time of memory. Storyworlds, 1(1), 99-114.

Brubaker, R. and Cooper, F. (2000). Beyond 'Identity' Theory and Society 29(1): 147.

Bruner E. M. (1996). Experience and its expressions. In Turner, V. W., \& Bruner, E. M. (1986). The anthropology of experience. University of Illinois Press, pp. $3-32$

Costall, A., \& Leudar, I. (Eds.) (1996). Situating action [special issue]. Ecological Psychology, 8(2), 101-187.

De Santillana, G., \& Von Dechend, H. (1977). Hamlet's Mill: An essay on myth and the frame of time. David R. Godine Publisher.

Demuth C. (2015a). New Directions in Qualitative Research in Psychology; Integrative Psychological and Behavioral Science.

Demuth C. B. (2015). Slow Food. Post-Qualitative Research in Psychology: Old Craft Skills in New Disguise? Integrative Psychological \& Behavioral Science DOI $10.1007 / \mathrm{s} 12124-015-9304-8$

Eakin, P. J. (1985). Fictions in autobiography. Studies in the art of self-invention. Princeton University Press, Princeton.

Fasulo A. (forthcoming). Walking the Autobiographical Path. The spatial dimension of remembering in a memoir by Italo Calvino, In A. L. Tota \&T. Hagen (eds.) Routledge International Handbook of Memory Studies. Routledge.

Fasulo A., Loyd H. \& Padiglione V. (2007). Children's Socialization into Cleaning Practices: a Cross-cultural Perspective. Discourse \& Society, 18, 11-33. 
Fasulo A. \& Piazza R. (2014). Introduction. R. Piazza and A. Fasulo (Eds.), Marked Identities: Narrating Lives between Social Labels and Individual Biographies. Basingstoke, UK: Palgrave Macmillan, pp.1-15.

Fasulo A. \& Zucchermaglio C. (2008). Narratives in the Workplace: Facts, Fiction and Canonicity. Text and Talk, 28, 3 351-376.

Fogel, A. (2011). Theoretical and applied dynamic systems research in developmental science. Child Development Perspectives, 5(4), 267-272.

Freeman, M. (2011). Toward poetic science. Integrative Psychological and Behavioral Science, 45 (4), 389-396.

Goodwin, C. (2000). Action and Embodiment Within Situated Human Interaction. Journal of Pragmatics, 32, 1489-1522.

Goodwin C. (2002). Time in Action. Current Anthropology, 43 (Supplement AugustOctober 2002): S19-S35.

Have, P. ten (2004). Understanding qualitative research and ethnomethodology. Sage.

Hutchins, E. (1995). Cognition in the wild. Cambridge, MA: MIT Press.

Kulick, D. (2005). The importance of what gets left out. Discourse Studies 7(4-5): 615-624.

Lave, J. (1988). Cognition in practice: Mind, mathematics and culture in everyday life. Cambridge: Cambridge University Press.

Schilbach, L., Timmermans, B., Reddy, V., Costall, A., Bente, G., Schlicht, G.T. \& Vogeley K. (2013) Toward a second-person neuroscience. Behavioral and Brain Science, 36(4):393-414.

Medved M. I. \& Brockmeier J. (2014). On the margins: Aboriginal realities and "White man's research." In R. Piazza \& A. Fasulo (Eds.), Marked 
Identities: Narrating Lives between Social Labels and Individual Biographies (pp. 79-97). Basingstoke, UK: Palgrave Macmillan.

Nucci, L. and Weber, E. (1995) Social Interactions in the Home and the Development of Young Children's Conceptions of the Personal. Child Development 66: $1438-52$.

Parker, I. (2004) Qualitative Psychology. Berkshire, UK: McGraw-Hill Education. Ricoeur, P. (2005). The Course of Recognition, trans. David Pellauer. Cambridge, MA: Harvard UP.

Ruppel, P.S. \& Mey, (2015). Grounded theory methodology - narrativity revisited Integrative Psychological \& Behavioral Science, 49.

Schegloff E. A. (1993). Reflections on Quantification in the Study of Conversation. Research on Language and Social Interaction, 26(1), 99-128.

Schilbach L., Timmermans B., Reddy V., Costall A., Bente G., Schlicht T., Vogeley K. (2013) Toward a second-person neuroscience. Behavioral and Brain Sciences 36 (4): 393-414 10.1017/S0140525X12000660.

Tateo, L. (2015). Gulliver's eggs: why methods are not an issue of qualitative research in cultural psychology. Integrative Psychological \& Behavioral Science, 49. doi:10.1007/s12124-015-9296-4.

Terkildsen, T., \& Petersen, S. (2015) The future of qualitative methods — a students' perspective. Integrative Psychological \& Behavioral Science, 49. doi:10.1007/s12124-015-9300-z.

Turner, V. W., \& Bruner, E. M. (1986) The anthropology of experience. University of Illinois Press.

Vom Lehn, D. (2014) Harold Garfinkel: The creation and development of ethnomethodology. Left Coast Press. 
Williams, V. (2011) Disability and discourse: Analysing inclusive conversation with people with intellectual disabilities. John Wiley \& Sons.

Williams, R. N., \& Gantt, E. E. (1998) Intimacy and Heteronomy On Grounding Psychology in the Ethical. Theory \& Psychology, 8(2), 253-267. 